\title{
Career Adaptability: The Key to Tackling Workplace Trauma at Scale
}

\author{
https://doi.org/10.3991/ijac.v14i1.21035 \\ Ian Hilder \\ Saffron Interactive, London, United Kingdom \\ infoesaffroninteractive.com
}

\begin{abstract}
Over the last 12 months, we have witnessed an acceleration of change within the traditional workplace. Digital disruption has only been exacerbated by Covid-19, displacement is rife, and the skills gap is widening exponentially. This report explores the concept of career adaptability, it's origin and development but also how it can form the backbone of the response to overcoming workplace trauma. Exploring a ground-breaking, human-centered response that will enable mentoring and employment support, at scale.
\end{abstract}

Keywords - Career adaptability, workplace trauma, videobot technology, skills assessment diagnostic

\section{Introduction}

Amidst the melee of Industry 4.0, the internet of things and process automation, it can be difficult to see where people fit in. The traditional workplace and the skills it demands have been changing rapidly. With companies and other commercial organisations increasingly reporting a skill shortage [1], their challenge is to recruit and/or retrain individuals to meet the ever-changing demands. For governments, the task, both locally and at a national level, is to prepare and provide those suffering from the displacement in the new landscape with on-going support [2] so that they can navigate this dynamic landscape.

The workplace was changing long before the spectre of Covid-19, but this virus has the potential to accelerate these changes at warp speed.

\section{Career Adaptability}

The new buzz term is Career Adaptability [3]. That is essentially an individual's ability or inclination to adapt their skills to meet changing demands throughout their working life. Companies need to engender this attitude in their workforce if they want to remain agile in the continuously transforming landscape. Furthermore, public authorities need to support individuals if employers cannot, so as to maintain employability. 
Mark Savickas has formulated a four-pillared framework around an individual's attitude to Career Adaptability, the Four Cs [4]:

- Concern: how much does the individual think about their future or is even aware of the issues?

- Control: how proactive is the individual, how disciplined, organised and deliberate are they in pursuing their goals?

- Curiosity: how much does the individual explore their options and ask the question "what will or could I do?"

- Confidence: how much faith does the individual have in their ability to achieve those goals?

The essential message of Career Adaptability is the higher the individual scores in each of the Four Cs, the better they can adapt to the changing marketplace. Jennifer Brimrose of Warwick University added a fifth C - Commitment.

This provides an essential framework and is important because the theory is based on research that is especially related to workplace trauma, very akin to the situation we find ourselves in today.

Using this framework, employers can embed the 4 (or 5) Cs into their Learning and Development strategy and performance measurement. This leads to better talent acquisition and succession planning, providing them with a flexible, resilient workforce that can adapt to the business' strategic imperatives quickly and with less trauma, a great way to avoid the intensive redundancy-rehiring yoyo that many organisations seem to go through.

\section{Progress to Date}

Identifying what needs to be done and the mechanism to do it seems simple enough. So, we just need to apply that and hey, presto! Everything in the garden is rosy. So how have the U.S. and Canada done on that score?

To answer that question, we can turn to 2019's update to the Survey of Adult Skills [5], curated by the Program for the International Assessment of Adult Competencies (PIAAC) in the U.S. This report was designed to provide insights into the availability of key skills in society and how they are used at work and home. Amongst its key findings it reports:

"Adults with more highly educated parents tend to have higher proficiency. Gaps related to family background are particularly pronounced in Hungary, Peru and the United States. Most of these differences are accounted for by individual characteristics, as people with highly educated parents also tend to attain higher levels of education themselves."

The reverse is also true:

"In the U.S., the odds of being low skilled are ten times higher for low-educated adults born to low-educated parents than for higher-educated adults born to highereducated parents, much greater than in other countries" [6]. 
Canada faces very similar issues and the effect of these disparities lead to a 'virtuous' and 'vicious' cycle, as detailed in the Canadian Ministers of Education analysis of the PIAAC findings:

"This can create a virtuous cycle for high-proficiency adults - and conversely, a vicious cycle for those with lower proficiency. When low-skilled adults lack access to learning or training opportunities, their skills remain weak or even deteriorate over time, compromising further their ability to participate in learning activities" [7].

If we think of that in terms of career adaptability, it is saying that those who start with the better academic qualifications, benefit most over time through further adult education and can best adapt in their careers. For those with a lower starting point, the reverse is true. So, if we apply Savickas' 4Cs, are we to conclude that those in the second group have the lowest concern, control, curiosity and/or confidence? That is possible, but another factor is likely to be in play; opportunity to participate and develop.

OECD (Organisation for Economic Cooperation and Development)'s follow on report, "Time for the U.S. to Reskill?" asserts that unless an active change is made to facilitate easier access to higher education or skills-building resources then the cycle will continue, with the interest and demand for further learning opportunities not being met for the groups who need it most:

"Among those low-skilled adults who did not participate in adult education, $18 \%$ representing around 3 million persons - say they would have liked to participate. Among low-skilled participants in adult education, 36\% say they would have wanted to participate more. [...] This suggests some unmet demand, which could be addressed by policy programmes" [6].

On the basis of this evidence, it is not too big a jump to conclude that the benefits of the digital revolution and career adaptability have benefitted some but left many behind.

\section{So How Do We Do Things Differently in the Current Climate?}

The overall lesson from OECD's report is that there has to be a rebalancing of opportunity towards those affected by inequities, "Action is needed to help low-skilled groups in the interest of equity and social cohesion. So while policy recommendations are addressed at basic skills improvement across the board, there is a particular focus on the low-skilled" [6]. And it is these same groups who, anecdotally at least, are being hit hardest by Covid-19.

At the same time, as Molly Courtice noted in her recent U.K. Skills Landscape article [8], 56\% of companies have had to drastically cut training budgets in 2020. This means that spending by government and other public sector organisations will become disproportionately more significant and grow as a share. Unfortunately, that is likely to be a levelling down rather than levelling up. 
Realistically, government spend is not going to be able to grow to cover all needs if we simply do more of the same and perpetuate the cycle. Clearly there is a need to do something smarter.

And maybe there is a clue as to what that "smarter" might be if we go back to Savickas' 4Cs. Though for negative reasons, a rebalancing as a result of the pandemic can be expected: the individual is likely to see an increase in Concern and Curiosity, whilst at the same time a loss of Control and Confidence.

So maybe that is where we need to put our efforts - Control and Confidence - by giving the individual the tools and guidance they need to help themselves. Or, as Noorie Sazen [9] has suggested: we need to provide another C - Capability. This is all about considering whether the individual has the resources and support that is needed - whether these are cognitive, financial or physical.

The issues of career adaptability in North America, outlined above, are replicated in the UK. In that same webinar, Noorie also showcased related initiatives where Saffron Interactive has already done work. The first is Value my Skills, a project for the UK-based trade union federation, TUC. The second is where this has now been completely redeveloped, into a project titled Create Your Own Future, thanks to the Nesta CareerTech Challenge [10], to include a ground-breaking, virtual video coach.

This coach is an AI-enabled videobot, that guides the user through the 5 Cs framework discussed above and also puts thought into action. The mentor helps the individual through a self-assessment of transferable skills, and the output is then modelled to personalised job profiles on the UK's national careers site which then also advertises current positions. The platform also allows learners to complete some level 1 and level 2 qualifications as well as soft skills courses. The videobot cajoles completion, motivates the user and supports them throughout. Live human help is also available through the national careers service or through union learning representatives. Crucially one other $\mathrm{C}$ - Capability associated with financial resources, at least - is covered as Saffron has made the experience entirely free and available to anyone and everyone that needs it. The platform can be accessed here [11].

The current state of career adaptability internationally leaves room for improvement and the need for change has never been more stark. Perhaps one silver lining of the pandemic is people's changing attitudes. But resources for this endeavour are squeezed and in increasing demand: simply doing more of the same is not going to cut it. There is a need for a radical shift in thinking. The CareerTech Challenge, funded by Nesta in partnership with the U.K. Government's Department for Education, is one example of such thinking and how we might meet the challenge, not just now but into the future.

The pandemic is a worldwide issue. Digital change is also worldwide, but also long term. By pooling resources, experience and building on what is already working we can aim to help everyone-low-skilled included - adapt to the challenge. By developing their skills, we improve their chances of getting back into or sustaining work and building a long-term career in a changing world. But as discussed, in order to make a true long-term difference in the employability landscape, it is vital we tackle these issues at their core. Ensuring both governmental resources and private innovations are 
making a measurable difference in key areas is crucial for long-term stability and an improvement within international career adaptability.

\section{$5 \quad$ References}

[1] https://www.youtube.com/watch?v=hdgGgSPl6oQ

[2] https://saffroninteractive.com/careertech-challenge-launch/

[3] https://saffroninteractive.com/get-in-touch/career-adaptability-learning-hub/

[4] Savickas, M.L. \& Porfeli, E.J. (2012) Career Adapt-Abilities Scale: Construction, reliability and measurement equivalence across 13 countries, Journal of Vocational Behaviour, 80, pp.661 -673. and Savickas, M.L. (2012) Life Design: A Paradigm for Career Intervention in the 21st Century Journal of Counseling \& Development 90 (1) 13-19

[5] OECD (2019), Skills Matter: Additional Results from the Survey of Adult Skills, OECD Skills Studies, OECD Publishing, Paris, pp 64

[6] OECD (2013), Time for the U.S. to Reskill? What the Survey of Adult Skills Says, OECD Skills Studies, OECD Publishing, Paris, pp 12-37

[7] Linda Jacobsen, Andrea Long (2018). The Health and Social Dimensions of Adult Skills in Canada Findings from the Programme for the International Assessment of Adult Competencies (PIAAC), Toronto, Canada.

[8] https://saffroninteractive.com/uk-skills-landscape/

[9] https://www.youtube.com/watch?v=ACrpMRt0xfo\&feature=emb_logo

[10] https://www.nesta.org.uk/project/careertech-challenge/

[11] https://createyourownfuture.unionlearn.org.uk/

\section{Author}

Ian Hilder is a Performance Consultant and Project Manager at Saffron Interactive, 1-7 Pilgrimage St, London, SE1 4LL, United Kingdom.

Ian has worked in the digital learning industry for 10 years and spent over 25 years in performance consultancy roles. He has worked with the likes of GSK, BP, Xerox and many more. Prior to becoming immersed in the world of digital learning and the employability space, Ian was at the forefront of innovation as early as 2000, when he managed a joint venture between Xerox and Gardners Books on a digitisation and "on-demand print" — one order, one copy_publishing service with an investment of $£ 2.2 \mathrm{~m}$ over 18 months.

Article submitted 2021-01-11. Resubmitted 2021-02-09. Final acceptance 2021-02-10. Final version published as submitted by the authors. 